\title{
Teachers' Lived Experiences about Teaching-Learning Process in Multi-Grade Classes
}

\author{
Seyyed Heshmatollah Mortazavizadeh ${ }^{1}$, Mohammad Reza Nili², Ahmad Reza Nasr Isfahani ${ }^{2} \&$ Mohammad $^{2}$ \\ Hassani $^{3}$ \\ ${ }^{1}$ University of Isfahan, Isfahan, Iran \\ ${ }^{2}$ Department of Education, University of Isfahan, Isfahan, Iran \\ ${ }^{3}$ Research Institute for Education, Tehran, Iran \\ Correspondence: Mohammad Reza Nili, Department of Education, University of Isfahan, Isfahan, Iran. E-mail: \\ m.nili.a@edu.ui.ac.ir
}

Received: June 25, 2017

Accepted: July 31, $2017 \quad$ Online Published: September 19, 2017

doi:10.5539/jel.v6n4p354

URL: http://doi.org/10.5539/jel.v6n4p354

\begin{abstract}
This study seeks to recognize teachers' lived experiences about teaching-learning process in multi-grade classes. The approach of the study is qualitative under the rubric of phenomenological studies. The statistical population consisted of the teachers of multi-grade classes in a non-prosperous province and a prosperous one. 14 teachers were selected using criterion sampling technique for an interview. The interviews were recorded and transcribed with the interviewees' permission; and they were analyzed using Creswell data analysis. In order to evaluate the validity of the questions, the viewpoints of experts in the field of educational sciences as well as some teachers experienced in multi-grade classes were taken into account. The reliability was approved through examination by the participants and asking from counterparts. The results showed that teachers of multi-grade classes in both provinces had similar views on using teaching methods, determining learning activities and grouping methods. However, they did not have the same views on determining the type of learning materials and resources. The results show that in multi-grade classes various teaching methods such as peer teaching and integrated teaching, leading resources and materials such as the local community, nature, and discarded materials and objects, different grouping methods such as adjacent grouping, row grouping, and sex grouping, and finally various learning activities including self learning and peer learning are utilized. Multi-grade teachers in the two provinces have similar viewpoints regarding teaching methods, learning activities, and grouping methods, but are of different viewpoints on kinds of learning materials and resources.
\end{abstract}

Keywords: curriculum, elements of curriculum, learning activities, multi-grade classes, teaching-learning process, teaching experience

\section{Introduction}

Despite the bulk of definitions for curriculum within the past few decades, since players in the field of education represent various values and experiences in the field, accomplishing an agreement or specialized consensus on the definition of curriculum is very difficult (Nasr, Etemadizadeh, \& Nili, 2011). Therefore, within the one-hundred-year history of curriculum development, different definitions have so far been provided, but no definition unanimously agreed upon can yet be provided. In this regard, curriculum is a complex concept and can be considered students' experience in a particular class or program in studying, usually leading to obtaining a degree of education (Null, 2012). Curriculum can be scoped over short periods of time, e.g., a single module, or it can be applied to several years of study. It can refer to the content, the teacher's intentions or plans, the structure of learning activities and assessment, the relationships between those activities and formally defined graduate and learning outcomes, or the change in skill, knowledge, and capability experienced by the student (Niculescu, 2009). Curriculum means the planned interaction of pupils with instructional content, materials, resources, and processes for evaluating the attainment of educational objectives (Indian Department of Education, 2010).

The concentrated curriculum of many countries has caused the content of multi-grade and single-grade textbooks not to be much different and multi-grade teachers and classes in the development of curricula of elementary 
schools not to be considered (Cash, 2000). Therefore, the curricula for primary school students in different countries are often designed specifically for single-grade classes. In Iranian curriculum system, which is among centralized systems, the curricula of multi-grade classes have no significant difference with those of regular classes in terms of objective and content. What distinguishes these two classes is teachers' activities in teaching-learning process. In addition to being in the same grades, students of single-grade classes are of the same gender and age, whereas multi-grade classes include two to six educational grade male and female students as well as students in different age groups.

Therefore, the elements of curriculum can be considered the foundations of educational activities so that paying attention to them can lead to improvement in the quality of teaching and learning activities. Although there is no general consensus on the elements of curriculum among experts, they have common points of view on four elements of objective, content, teaching method and evaluation (Kridel, 2010). One of the most comprehensive classifications related to the elements of curriculum is Cline's view (1991). He considered the elements of curriculum including objectives, content, teaching methods, learning materials and resources, learning activities, evaluation methods, grouping methods, and training time and space (Mehr Mohammadi, 2002). It is the teacher who makes the curriculum and its different elements compatible with the nature of multi-grade classes. Research shows that among the above-mentioned elements, just four elements of teaching methods, learning materials and resources, grouping methods, and learning activities have a particular difference in multi- and single-grade classes. Multi-grade classes are those in which teachers teach at least two different grades, while some have to teach three, four, five or even six different grades in the new national curriculum. A number of terms such as multi-grade, mixed years, combination class, vertical grouping, family grouping, composite class, split class, double class, and unitary schools are used for the description of multi-grade situations around the world (Little, 2006).

Usually, students in such classes are heterogeneous in terms of age, gender, ability, skill, and educational grade, and are taught in one class and by a single teacher within the academic year. In these classes, the teacher teaches more than one subject in a few consecutive hours for different grades.

Teaching in multi-grade classes is a form of education, which can meet the needs of many different countries as far as improving and developing teaching-learning process, eradicating illiteracy and achieving universal education are concerned because there are schools with a few students in many remote areas and border towns and even in some cities. In such cases, if their education is not taken into account, they will quit or migrate with their families to more populated areas. Paying attention to these schools and coverage of education-required children are educational objectives and programs in different countries (Mortazavizadeh, 2014). The nature of these classes is in such a way that the teacher divides the time for a training session into the number of grades in the class, and students are involved in self-learning, peer-learning, and individual and group teaching-learning processes more than they are exposed to teacher's teaching. In such cases, the teacher does not have enough opportunity for grade to grade training, whereas in single-grade (regular) classes, students are the same in a grade and similar to each other in terms of age and sex having fewer differences in terms of abilities and skills and a full-time teacher is assigned to teach them (Mortazavizadeh, 2014).

Multi-grade classes encompass a substantial portion of education in developed and developing countries. In fact, the number of students in multi-grade classes is increasing. In developing countries, the increase in multi-grade classes is caused by an attempt to increase accessibility to elementary education, especially for girls through establishing schools close to rural communities (Thomas \& Shaw, 1992). In some areas, especially in low population areas, schools are very sparse, and one or two teachers are responsible for teaching students at different grades due to the low number of students (Little, 2006). Similarly, in the situations where many students sign up and there is a shortage of teachers, more than one grade may be placed in one class and taught by one teacher. Multi-grade teaching began as a means to overcome the shortage of teachers and help achieve "Education for All" (EFA). EFA was a global movement seeking to improve the quality of and access to education for everyone regardless of age, color, or race until 2015 (Little, 2006). This movement has six objectives including:

1) Accessing to and improving education and early childhood care.

2) Accessing to and completing free and compulsory primary education with good quality for all, particularly girls, children in difficult circumstances and those belonging to ethnic minorities.

3) Providing appropriate programs and life skills for all the youths and adults.

4) Improving the level of adult literacy. 
5) Eliminating gender disparities.

6) Improving all aspects of education quality (Little, 2006).

Education in multi-grade classes creates an opportunity for interaction among learners with different ages, stages of development, grades, and abilities since variety and differences are high among learners in such classes (Berry, 2012). According to UNESCO experts (2013), in many countries, however, not only in Southeast Asia, but also in many parts of Europe, North America, and Australia, multi-grade teaching is the first choice for managing a classroom. This is true for several reasons:

1) It helps children, especially those in remote and isolated areas, realize their right to education and therefore learn what they need and want to learn.

2) It is a cost-effective approach to providing schooling to children often excluded from the education system.

3) It encourages children from different backgrounds to learn with the help of their peers and therefore promotes cohesiveness, cooperation, and healthy competition among students, strengthens interpersonal and leadership skills and develops a positive attitude towards sharing.

4) It benefits you as a multi-grade teacher by helping you to plan your work better and be more efficient in your use of time.

5) Through the variety of teaching practices used in multi-grade classrooms, it contributes to your students' cognitive development.

According to researchers (Asadi, 2011; Behnam Hashtjin \& Saedi Zargabad, 2011; Abdi, 2004; Little, 2006; Berry, 2012; Aghazadeh \& Fazli, 2013; Mortazavizadeh, 2014; and Bashiri Haddadian, Mahmoudi, Rezapour, \& Adib, 2015), multi-grade classes face problems such as lack of sufficient time, low information and experiences of teachers, wide responsibilities of teachers, low knowledge and information of students, low population of students, inappropriate age and gender composition of students, high diversity of courses, number of grades, lack of learning materials and resources, inappropriate training spaces, distraction of some students, and multilingual or bilingual students.

A good curriculum should be able to consider all the elements in the curriculum; however, these problems have caused the teacher to fail to coordinate curriculum elements and, in many cases, some elements have been neglected. For example, low population of students prevents the formation of small groups and group collaborative activities. All the aforementioned problems expose the teachers to lack of sufficient time so that they cannot go through teaching-learning processes at a reasonable speed. Most domestic studies have examined the elements of curriculum in different courses while no study has so far been conducted on the elements of curriculum in elementary grades, especially in multi- and single-grade classes. Furthermore, most studies conducted on multi-grade classes deal with issues and problems in which the managers and teachers of the country's educational system are involved, and the administration of these classes and the elements of the curriculum in these classes have not been investigated.

\section{Research Objectives}

In the present investigation, the researcher intends to follow four objectives of,

1) Investigating teaching methods in multi-grade classes.

2) Investigating learning materials and resources in multi-grade classes.

3) Investigating grouping methods in multi-grade classes.

4) Investigating learning activities I'm multi-grade classes.

Therefore, the present study investigates the four elements of teaching methods, learning materials and resources, grouping, and learning activities. The following gives a description of each element.

1) Teaching methods are a set of regular measures adopted by a teacher for directing the activities in order to achieve instructional objectives according to conditions and facilities. All over the history, teachers and administrators of curriculum have used various methods, which have always been changed and evolved given available facilities and the emergence of new ideas (Shaabani, 2011, p. 273). Teaching method determines teacher's duties and paves the ground for the activities of the students in the classroom, and its success depends on the quantity and quality of the students' learning. In a teaching process, behavioral science specialists have divided teaching methods into different codes such as old and new, active and passive, interactive and non-interactive, far and near, direct and indirect, and teacher-centered and learner-centered methods. Teachers 
should take an inspiration from these methods and select the best methods for teaching-learning processes in the classroom (Nasr, 1993). If teaching methods are effective and efficient, they will lead to desirable objectives (Gutek, 1997; translated by Pakseresht, 2005).

Teaching methods in multi-grade classes depend on teacher's capability, subject, lesson's objectives and class position so that in the study entitled "Investigating teaching methods in multi-grade classes in Austria and Finland", Beihammer and Hascher (2015) postulated that teaching methods were widely different in multi-grade classes and were related to the teacher's personality, teaching subjects and situations. Hence, it is not possible to identify the most common method.

2) Learning materials and resources are resources such as human resources, educational materials, and educational space, which the learner uses alone or in combination with each other (Afzalnia, 2005). The necessity to use learning materials and resources other than textbooks in teaching-learning process over the past decades has attracted many stakeholders in the education system in different countries. Such attention has been multiplied in multi-grade classes because of their special features. Local community can contribute to create and share the resources and support multi-grade classes. Networks and partnerships with groups such as NGOs can also provide suggestions to improve classroom teaching (UNESCO, 2013). Each multi-grade teacher requires different resources appropriate to students' various needs such as the class board, radio, television, computer, textbooks, teacher's guide, newspapers, magazines, tangible objects easily available in the environment, raw materials such as empty boxes, cans, bottles, stone, wood, seeds, shells, animals, insects, and sand are readily available (Mkosana \& Kapesa, 2004).

3) Grouping refers to the groups within the class, which differs in terms of content and teaching-learning strategies (Fathi \& Ejargah, 2015). Group work is a good way to organize the classroom, is learner-centered, and can be used at all times (UNESCO, 2013). Grouping the students is a key factor in organizing multi-grade classes (Beihammer \& Hascher, 2015).

The process of forming a group mainly follows two approaches: grouping the students purposefully based on age, grade, and ability; and grouping them - based on different fields. The primary groups are often formed on a semi-fixed basis during the educational weeks and are often designed to cover certain parts of the curriculum deeply and in different grade levels. Other ways to organize groups can be discovered and applied to fit the age and maturity levels of students. To accomplish this task, activities that do not require the direct supervision of a teacher can be created. Such activities are based on the groups with the same abilities, different abilities, peer learning, and a wide range of individual tasks such as solving math problems or writing exercises (UNESCO, 2013). There are four major grouping methods of,

Inter class ability grouping,

Intra class ability grouping,

Cooperative learning,

Individual instruction (Mathot, 2004).

4) Learning activities: Another element of the curriculum is learning activities that is different in multi-grade and single-grade classes and refers to learners' involvement in learning, which leads to learning experiences. The higher the level of involvement and learning activities, the deeper the learning experiences will be (Fathi Vajargah, 2015). Multi-grade classes are multidimensional classes and are spaces for educational activities such as reading, writing, listening and speaking. Many classroom activities occur at the same time in a way that some students are involved in mutual training, some listen to the teacher, and others work individually on their homework. Selecting and organizing activities are the requirements for the good management of multi-grade classes. The teacher should have a clear idea on selecting the best types of activities for different groups and on how to divide students based on different grades and age levels. This helps the teacher design activities appropriate for multi-grade situations (UNESCO, 2013). Usually, seven types of learning activities are performed in most multi-grade classes consisting of: 1) Quiet or individual study, 2) test, 3) teaching whole students, 4) collaborative work, 5) group discussions, 6) working with audio-visual media, and 7) peer-teaching or training in small groups (Miller, 1990). Therefore, the teacher can involve students individually or collectively in training activities such as considering teacher teaching, playing, role playing, experimenting, observation, preparing maps, graphs, and tables, giving dictations, writing compositions, independent study, reviewing new lessons, evaluating each other, etc. (Mortazavizadeh, 2015).

Although some teachers in multi-grade classes may not have achieved a lot of information in the field of elements of curriculum, they have valuable experiences. Getting familiar with these experiences can help expand 
knowledge about learning-teaching process in multi-grade classes. Therefore, the present study used the rubric of phenomenological studies to understand teachers' lived experiences about the four elements of curriculum.

\section{Methodology}

This study was qualitative under the rubric of phenomenological studies. Phenomenology is done to describe and interpret specific experiences from perspective of people who have had them. Phenomenologist's aim at manifesting the complexity of the meaning of experiences (Razavieh, 2013). The study population consisted of teachers working in multi-grade classes in a non-prosperous province and a prosperous one in the academic year of 2015-2016.

The primary motivation of the researchers to select the above-mentioned elements was that these elements are often the results of what happens within the classroom and are neglected by teachers in multi-grade classes. Since in this study, the educational experience of teachers teaching in multi-grade classes and passing educational courses related to these classes are the main assumptions, selecting people with the above features was essential. Therefore, criterion-sampling technique was used. Using this technique involves the selection of items fulfilling important criteria. This strategy is useful especially for studying educational programs (Gall, Borg, \& Gall, 1996; quoted by Nasr et al., 2000, p. 393). To participate in the study, 14 teachers with features such as employment in the Department of Education, having more than 8 years of experience in teaching multi-grade classes, and training courses related to teaching in these classes, were selected so that they could provide the best information. Participants held Bachelor's Degrees, and 8 of them had between 8 and 11 years of teaching experience in ordinary classes, and the others had 11 years of teaching experience in multi-grade classes.

The data were collected through semi-structured interviews with these people. Collecting data continued until the researcher found that the new finding could not be obtained, and practically the continuity of data collection was the replication of the previous findings. With respect to the achieved theoretical saturation, data collection was stopped.

Presenting the research objectives and ensuring the interviewees on the confidentiality of their names, interview time was agreed upon with each participant and the interviews were generally performed in school and in a suitable room. 12 individuals were interviewed. 2 people did not let the researcher record their voices; therefore, the researcher personally wrote down the dialogues within the interview. The interview time ranged from 50 to 80 minutes. All interviews were held by one researcher. The interviews began with a general topic, and the interview process continued based on the content expressed and was followed by questions to cover the research purposes. After the texts were transcribed and studied, it became evident that some teachers' explanations were ambiguous. To remove uncertainties, the participants were asked for additional explanations through phone.

In order to analyze the data from interviews, Creswell and Clark data analysis (2007) (translated by Kiamanesh \& Sarayee, 2011) was used. In doing so, the following steps were taken for data analysis: data provision, data organization, data reduction and summarization in the form of the categories through coding and combining the codes, and finally data presentation in tables. Accordingly, after several text implementations and precise reviews of the detailed answers of the participants, the categories were identified and selected.

To evaluate the validity of the questions, the viewpoints of Educational Science teachers as well as several teachers experienced in teaching multi-grade classes were used. To assess the reliability of the questions, i.e., the assessment of whether the information obtained through gathering qualitative data is accurate or not, an investigation by the participants (Cresswell \& Clark, 2007; translated by Kiamanesh \& Sarayee, 2011) was used as a conventional method. To do this, the researcher gave a summary of the findings to the participants in the study, and asked them to study them and ensure whether the data accurately reflected their experiences or not. In addition, a few faculty members familiar with qualitative research were consulted on the results of the analysis and classification of the interviews.

\section{Research Findings}

The findings of the analysis of the interviews were 33 categories, which were discussed and worked out of the four mentioned elements. For the element of teaching methodology, learning material and resources, grouping, and learning activities 9, 5, 7, and 12 categories were, respectively, collected and formulated. In the following, some explanations are provided: 


\subsection{Teaching Methods}

In an interview with teachers in multi-grade classes, 9 categories were identified on teaching methodologies.

All the categories are given in Table 1.

Table 1. Categories related to teaching methods

\begin{tabular}{llllllll}
\hline Row & Teaching method & Frequency & $\begin{array}{l}\text { Frequency } \\
\text { percentage }\end{array}$ & Row & Teaching method & Frequency & $\begin{array}{c}\text { Frequency } \\
\text { percentage }\end{array}$ \\
\hline 1 & Peer tutoring & 14 & 100 & 6 & Experimental & 7 & 50 \\
2 & Centered or individualized & 11 & 78 & 7 & Project & 7 & 50 \\
3 & Question and answer & 10 & 71 & 8 & Role play & 5 & 35 \\
4 & Group discussion & 8 & 57 & 9 & Problem-solving & 5 & 35 \\
5 & Brainstorming & 8 & 57 & & & & \\
\hline
\end{tabular}

According to teacher No. 5, in order to deliver the content, the teacher of a multi-grade class can use varied teaching methods such as cooperative teaching, group teaching, central teaching and integrated teaching, peer teaching and teaching by local community members; while in single-grade classes, such methods are not used.

In this regard, interviewee No. 12 believes that the teacher in a multi-grade class can use an integrated method because it lets the teacher teach students of two to three grades simultaneously, which saves time as well. According to interviewee No. 11, various teaching methods can be tailored to the situation of a multi-grade class so that students can be active; however, some teaching methods such as participatory method, question and answer, assistant teaching, field trips, and brainstorming are more applied.

\subsection{Learning Materials and Resources}

In the interview on learning materials and resources for multi-grade classes, with teachers of multi-grade classes, five categories were identified, as presented in Table 2:

Table 2. Categories related to learning materials and resources

\begin{tabular}{cccc}
\hline Row & Category & Frequency & Frequency percentage \\
\hline 1 & Human resources & 14 & 100 \\
2 & Nature & 12 & 85 \\
3 & discarded materials & 11 & 78 \\
4 & Educational adis & 11 & 78 \\
5 & Educational space & 10 & 71 \\
\hline
\end{tabular}

Human resources consist of teachers, students, and local community including parents, local clergy, rural municipality, healthcare assistant, and other people residing around multi-grade classes. Nature is a great resource for gathering important data for teachers and students in multi-grade classes. Since, unlike urban schools, a large number of their classes are located adjacent to nature, it can be used easily and quite inexpensively. Discarded materials are divided into two categories of waste household and industrial equipment, and in multi-grade classes, waste household equipment are used more. Learning tools in these classes are boards, cell phones, new technologies, and mass media. Teaching space in villages includes school space, mosque, and houses of scholars or someone who has a personal library and students sometimes go together to these places and have discussions in addition to using the books.

In nature, creatures are living on and within the earth, in the seas, rivers, mountains, deserts, plains, and forests. For example, animals such as earthworms, ants, rats, red bees and badgers live within the earth, while many other animals live on the earth. Students in rural and nomadic areas can easily become familiar with a variety of animals, plants, rocks, and soils. Therefore, using nature is an appropriate opportunity for teachers in multi-grade 
classes. In this way, they can make the learning-teaching process objective and delightful for students (interviewee No. 12).

Interviewee No. 11 says that learning resources in multi-grade classes consist of nature, textbooks, teacher, other students, and the people outside of school including parents, neighbors, high school students, healthcare assistant as well as mass media such as television, radio, magazines, newspapers, and mobile phones. The situation of multi-grade classes is affected by the rural population, the existing facilities far or close to the town, road, and nature. The richer the position of the village, the wider the learning resources can be.

In this regard, interviewee No 1 says that the number of households is very low. Therefore, there is no health home, mosque, library, home of scholar, and high school. Some multi-grade classes are located in very small villages and do not have any of the resources mentioned above, but parents are the only important and valuable sources from whom students can obtain necessary information with the management and guidance of their teachers as they have great experiences and help students learn the subject matter well. Nature is another learning resource including trees, birds, animals, and rocks that help students learn science, Persian and even mathematics.

The most important means of education in remote areas are found in nature. In mathematics, thin branches of trees can be used to classify the numbers, and in science, plants can be used to teach roots, stems, and leaves. Discarded items such as cans can be used to teach volume, occupying space and chemical change (rusting). Cartons can be used to make whirligig, too. By the students can be assigned to local people. The works to the local community that lead to repetition and practice of the content on students because they cannot teach them new materials. Things like questions for students and monitoring their work in homework can be assigned to them (interviewee No. 9).

\subsection{Grouping Methods}

In the interview on the appropriate methods for grouping with the teachers of multi-grade classes, in multi-grade classes, 7 categories were identified as presented in Table 3.

Table 3. Categories related to grouping methods

\begin{tabular}{cccc}
\hline Row & Grouping method & Frequency & Frequency percentage \\
\hline 1 & Adjacent grades & 13 & 93 \\
2 & The same row & 12 & 85 \\
3 & Gender & 7 & 50 \\
4 & Students' abilities & 7 & 50 \\
5 & Local community & 5 & 35 \\
6 & Subject matter & 2 & 14 \\
7 & Random & 2 & 14 \\
\hline
\end{tabular}

In the interview with the teachers, they said that group activities in multi-grade classes saved time and improved the quality of teaching-learning activities. However, in the current situation, grouping in an authentic way in multi-grade classes is not possible, first, because of the number of students in most classes, and second, because there is not enough space to do group work in the classes where the number of students is good to form a group. However, the task of teachers is crucial in shaping different types of groups.

Most teachers, including interviewee number 11 believe that due to low number of students in each grade, group work cannot be done in multi-grade classes, and that teachers are forced to put students of adjacent grades in one group to do group activities together. However, sometimes this type of grouping causes students not to learn concepts related to their course materials as in adjacent groups, concepts related to one grade are discussed and often course materials of lower grades are the subject under discussion.

Emphasizing the above statements, another teacher says because the number of students in each grade is low, local grouping, row grouping, age grouping, and grouping of neighboring grades are the most common groupings in multi-grade classes and when the number of students is large, they are grouped together based on their abilities. It should be noted that in this case, the members are always fixed and they cannot be changed (interviewee No. 2). 
Sometimes the grades are distant from each other and grouping from other grades is impossible. Sometimes students of adjacent grades are at the center of teaching, sometimes the subject matters of the students of adjacent grades are not clearly similar and sometimes the students of adjacent grades do not cooperate with each other. However, with the guidance and encouragement of teachers, students can be grouped since group activities improve the quality of student learning and save time (interviewee No. 5).

\subsection{Learning Activities}

In the interview on learning activities and types in multi-grade classes, with the teachers of multi-grade classes, 12 categories were identified as given in Table 4:

Table 4. Categories related to learning activities

\begin{tabular}{|c|c|c|c|c|c|c|c|}
\hline Row & Learning activities & Frequency & $\begin{array}{l}\text { Frequency } \\
\text { percentage }\end{array}$ & Row & Learning activities & Frequency & $\begin{array}{l}\text { Frequency } \\
\text { percentage }\end{array}$ \\
\hline 1 & Self-study & 11 & 78 & 7 & Storytelling & 5 & 35 \\
\hline 2 & Peer learning & 10 & 71 & 8 & Art work & 5 & 35 \\
\hline 3 & Peer assessment & 9 & 64 & 89 & Testing & 5 & 35 \\
\hline 4 & Exercising & 8 & 57 & 10 & Self-evaluation & 4 & 28 \\
\hline 5 & Dictation & 7 & 50 & 11 & Summarizing & 4 & 28 \\
\hline 6 & Group discussion & 6 & 42 & 12 & Preparing educational equipment & 3 & 21 \\
\hline
\end{tabular}

The dynamism of multi-grade classes depends on the quality of activities that the teachers design, develop, and implement. The more the activities are varied and enriched, the higher the quality of teaching and learning activities will be. In multi-grade classes, students who are not at the center of teaching are generally involved in activities such as peer education, bilateral asking, reading, and solving the problems of others (interviewee number 4).

According to interviewee No. 7, activities such as asking each other questions and discussions can be determined for students in multi-grade classes. In addition, when teachers teach students of one grade, students of other grades can do activities such as painting, self-study, and exercises related to class work so that time can used for training students in other grades.

Interviewee No. 11 says in order to save time and deal with educational affairs of students, the teacher should try to determine the types of activities for each grade in a written form before entering the classroom without wasting time. When the teacher wants to teach students of one grade, he should not keep students of other grades idle, but he had better give them targeted activities to do.

\section{Discussion and Conclusion}

The main objective of this study was to understand the lived experiences of the teachers of multi-grade classes about the four elements of Klein curriculum elements of including teaching methods, learning materials and resources, grouping, and learning activities. The results illustrate that the implementation of teaching-learning processes in multi-grade classes is greatly different from those in single-grade classes. These differences result from the heterogeneity of students, differences in the way they learn, and the teacher's activities. In teaching-learning process in multi-grade classes, the elements of teaching methods, learning materials and resources, grouping methods, and learning activities were investigated.

A curriculum will have the necessary efficiency only when the performances of each of its elements are mutually reinforcing each other. If so, curriculum will have the most favorable capacity to affect the students' performance. These elements are closely related to each other and are inseparable from each other. A change in any of the above mentioned elements will change other elements. The more the elements are coordinated and the more desired the elements are run; the more it is possible for the students to actualize their capabilities. The results of the analysis of the interviews in relation to teaching methods suggested that the teachers of multi-grade classes should use various teaching techniques such as peer teaching, integrated teaching, and other teaching methods provided that they are localized to suit their class conditions. In this way, they can achieve the desired objectives. Teaching methods which are different from those employed to teach students in the sixth grade. Therefore, the teacher 
should be aware of all teaching methods and in one session, he may use several methods to teach the students. This finding is consistent with the research findings obtained by Harry Byahamr and Hatcher (2015).

Finding show that Multi-grade classes often lack training equipment and facilities as well as educational equipment because many of these classes are held in remote, mud and brick schools, and some of them are very small and there is no janitor, and no one takes care of such schools when the teacher is not there. Moreover, many of them lack educational facilities and required materials. However, due to their location in the nature, these schools enjoy a good command of first-hand materials and resources. The teacher can also obtain the required educational materials and equipment with the help of the students and their parents. According to the findings in the present study, local community and nature are the most important learning resources in these classes. These findings are somewhat consistent with the findings of Miller (1990), Mkosana and Kapesa UNESCO (2013).

Results obtained in connection with the method of grouping focuses on two main axes: Firstly, sufficient number of students is required for grouping. If the number of students in each grade is not enough to form groups, there is no possibility of forming groups on any grade; and secondly, a sufficient number of students in the class (all grades together) is considered because grouping methods in multi-grade classes are often adjacent grouping, row grouping, gender grouping, and are ultimately based on ability. Grouping methods in multi-grade classes have a significant difference from those in single-grade classes. For example, in some grades, the number of students is not enough to form groups. In this case, UNESCO (2013) recommends that if the number of students in each grade is not sufficient for grouping, put adjacent grades in one group. However, single-grade classes allow the formation of groups in various methods and do not have the problems of grouping in multi-grade classes, in which sometimes the number of students is one or two in one or more grades, and in some other grades, the number of students is more than three people. Such combinations allow the teacher to select his grouping method according to his class status so that he can facilitate cooperation and active participation of students in different grades. As UNESCO (2013) points out, certain matters need groups with different skills, while others need to take advantage of the whole class. Some need to be re-trained, some require independent assignments and some need learn self-directed learning with regular support from the teacher and other students. Although the teachers pointed out the low number of students as a major obstacle to group multi-grade classes, they argued that students could be grouped using methods such as adjacent grade grouping rand row grouping based on ability grouping, subject matter grouping, gender grouping, random grouping. Experts argue that education in multi-grade classes has the best performance where students can work together because knowledge is achieved through active participation. Teachers need to desert the philosophy of transfer-based education in a single-grade class and turn to ways that encourage students to take advantage of each other's experiences (Mulryan-Kyne, 2005).

Research finding show that students are grouped based on adjacent grades grouping, row grouping, gender grouping and ability finding of the study are consistent white Mathot (2001) and UNESCO (2013). In connection with learning activities while emphasizing on activating the students in multi-grade classes, teachers of multi-grade classes, based on their experiences, believed that the teacher could engage students in the learning process using methods such as self-learning, peer learning, self assessment, peer assessment, summarizing, group discussion, preparation of educational equipment, testing, exercising, doing artwork, and storytelling. This is in line with the findings by Miller (1990), Mathot (2001) and UNESCO (2013).

The results indicated that teachers of multi-grade classes in the two provinces had similar views on the use of teaching methods, determining learning activities and ways of grouping. However, they did not have the same perspectives in determining the type of learning materials and resources. Teachers of multi-grade classes in the prosperous province emphasized using new technologies in their classes after using local community, nature, teacher and discarded materials, whereas in the non-prosperous province, the teachers put the new technologies last in priority. It is suggested to combine students of close rural schools for effective use of a variety of teaching methods, learning materials and resources, grouping students and implementing different learning activities in multi-grade classes. In doing so, students of fourth, fifth and sixth grades can be sent to neighboring schools so that on the one hand, the amount of teacher's activities is decreased and more opportunities are provided for educational process in the classes, and on the other hand, collaborative work and designing learning activities become possible.

This study directly addresses the Ministry of Education and invites it to educate professional teachers in multi-grade classes through forming in-service classes associated with teaching-learning processes. In addition, teachers teaching in multi-grade classes may take advantage of the results of this study to improve teaching-learning activities in their own classes. 


\section{Acknowledgements}

I would like to express my sincere appreciation to all teachers, students and multi-grade experts for their cooperation and assistance in the process of this research.

\section{References}

Abdi, H. (2004). Investigating instructional problems in multi-grade classes, according to study design. East Azerbaijan: Education Department.

Afzalnia, M. (2005). Designing and familiarity with the centers of learning materials and resources. Tehran: Samt.

Aghazadeh, M., \& Fazli, R. (2013). Training guide in multi-grade classes. Tehran: Ayyej.

Asadi, P. (2011). Investigating the problems of teaching methods and multi-grade classes and providing more appropriate teaching methods in multi-grade classes in Golpayegan, Isfahan, according to study design. Isfahan: Isfahan Education Organization.

Bashiri Haddadan, K., Mahmoudi, F., Rezapour, Y., \& Adib, Y. (2015). Describing Teachers and experts' perception and experiences of education in primary schools Multi-grade classrooms in Kaliber Villages. Shahed Biannual Peer Review Training and Learning Researches, 22(7), 107-120.

Creswell, J. A. C., \& Plano. (2011). Mixed Methods Research (A. Kiamanesh, \& J. Saraii, Trans.). Tehran: Ayyij Publication.

Fathi, K. et al. (2015). Concepts and principles of curriculum. Tehran: Elm Ostadan.

Gerald, L. G. (2010). Philosophical and Ideological Perspectives on Education (M. J. Pakseresht, Trans.). Tehran: Samt.

Hashtjin, B. S. A., \& Saedi, A. (2001). Examining problems and issues of multi-grade classes. Khalkhal: Payam-e Noor University.

Iman, M. (2009). Paradigmatic foundation of qualitative and quantitative research methods in humanity. Qom: Research Institute of Howzah and University.

Mathot, G. B. (2001). A handbook for teachers of multi-grade classes. UNESCO.

Mehrmohammadi, M. (2002). Curriculum, perspectives, approaches and views. Tehran: Samt.

Meredith, D., Gall Walter, R., \& Borg Joyce, P. G. (2010). Educational Research an Introduction (A. R. Nasrm, Trans., Vol. 1). Tehran: SAMT.

Mortazavizadeh, H. (2014). Teaching guide in multi-grade classes. Tehran: Abed.

Mortazavizadeh, H. (2015). Management and scheduling of multi-grade classes. Tehran: Koresh.

Nasr Esfahani, A. (1993). Factors affecting the quality of improvement. Education, 3(23).

Nasr, A., Etemadizadeh, H., \& Nili, M. R. (2011). Theoretical and practical program approaches in formulating curricula in higher education. Tehran: Samt.

Razavieh, A. (2013). Research Methods in Behavioral Sciences, Shiraz. Shiraz: Shiraz University.

Shabani, H. (2011). Education skills. Tehran: Samt.

\section{Copyrights}

Copyright for this article is retained by the author(s), with first publication rights granted to the journal.

This is an open-access article distributed under the terms and conditions of the Creative Commons Attribution license (http://creativecommons.org/licenses/by/4.0/). 